e-Polymers 2001, no. 010.

\title{
Photoinitiated cationic polymerization using allylsulfonium salts. Substituent effect on the initiator activity
}

\author{
Fatma Bayramoglu, Aysen Onen, Yusuf Yagci *
}

Istanbul Technical University, Department of Chemistry, Maslak 80626, Istanbul, Turkey; yusuf@itu.edu.tr

(Received: June 5, 2001; published: August 8, 2001)

\begin{abstract}
Allylthiophenium salts with various substituents at the allylic moiety were synthesized, characterized and shown to be efficient coinitiators in radicallly promoted cationic photopolymerization of cyclohexene oxide. The relative efficiencies of these salts in combination with benzoin and benzophenone as free radical sources in the photopolymerizations are compared. Both additionfragmentation and electron transfer mechanisms are proposed and their relative merits discussed.
\end{abstract}

\section{Introduction}

During the last two decades, significant improvement has been made in the area of photoinitiated cationic polymerization [1,2]. Especially in industrial purposes, this chemistry has practical applications in areas such as printing, coatings, adhesives, microelectronics and resist technology. Thus far, the most efficient cationic photoinitiators are diaryliodonium [3,4], triarylsulfonium [5], $\mathrm{N}$-alkoxypyridinium salts [6-8] with non-nucleophilic counteranions. These salts can be activated directly at wavelengths below $300 \mathrm{~nm}$. Their spectral sensitivity can also be shifted to higher wavelengths by the use of free radical sources [7], photosensitizers [8] and charge transfer complexes [9] which increases their utilization in commercially important technologies [10]. We extended the idea of wavelength selective initiating systems to the specially designed allylic salts [11-20] of the following structure to find that they serve as highly reactive cationic co-initiators in conjunction with free radical photoinitiators.

It was shown that the reactive species capable of initiating cationic polymerization are formed by the fragmentation reaction following up the addition of free radicals generated by light (also by heat) to the double bond of the allylic salts. It is, therefore, extremely easy to tune the polymerization to a desired wavelengths' range (the emission of the irradiation source used) by choosing appropriate radical initiators. Significant features of the allylic salts involve the possibility of activity control by substituents at the allylic moiety as well as by the structures of both allylic salt and free radicals generated [13]. This paper describes the synthesis of several sulfonium salts and the effect of substituents $(R)$ at the allylic moiety on the initiator activity in the photopolymerization of cyclohexene oxide $(\mathrm{CHO})$. 

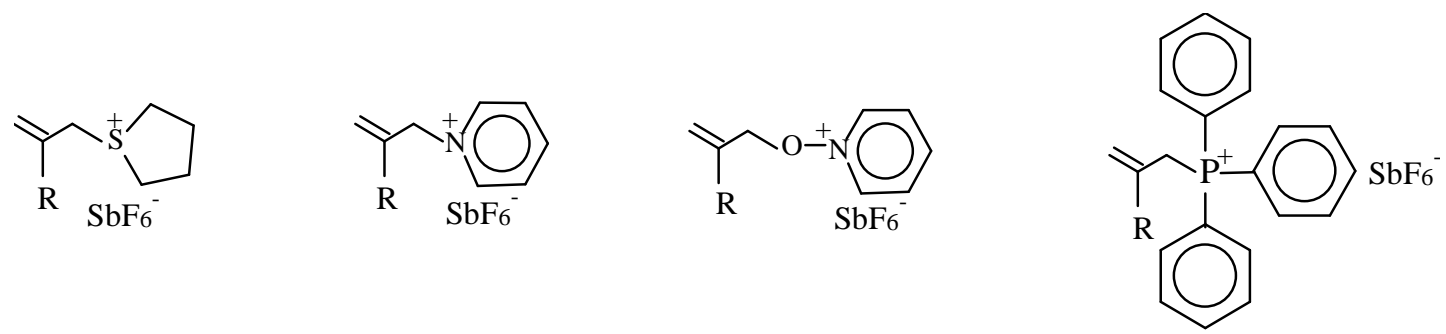

$\mathrm{R}=\mathrm{COOEt}$

\section{Experimental part}

\section{Materials}

2-Ethoxycarbonyl-2-propenylthiophenium hexafluoroantimonate (EAT) was prepared as described previously [11]. Tetrahydrothiophene (Fluka), 3-bromo-2-methylpropene (Fluka), allyl bromide (Fluka), $\mathrm{NaSbF}_{6}$ (Aldrich) were used as received. Benzophenone (Fluka) was recrystallized from heptane. Benzoin (Fluka) was recrystallized from ethanol. Monomers and solvents were purified by conventional drying and distillation procedures.

\section{Synthesis of 2-propenyltetrahydrothiophenium hexafluoroantimonate (AT)}

A mixture of $0.5 \mathrm{ml}(5.67 \mathrm{mmol})$ allyl bromide and $0.47 \mathrm{ml}(5.67 \mathrm{mmol})$ tetrahydrothiophene was stirred $1 \mathrm{~h}$ at room temperature. The whitish precipitate was dissolved in distilled water and washed with diethyl ether. Then an equimolar amount of $\mathrm{NaSbF}_{6}(1.46 \mathrm{~g})$ was added to the aqueous portion and a white precipitate of AT was collected, washed with water and dried; m.p. $92-94^{\circ} \mathrm{C}$, yield $42 \%$.

${ }^{1} \mathrm{H}$ NMR ( $\delta$ in ppm): $5.9-6.15, \mathrm{CH}_{2}=; 5.6-5.8,=\mathrm{CH}-; 4.1,-\mathrm{CH}_{2}-\mathrm{S}^{+} ; 3.56-3.73$, $-\mathrm{S}^{+}-\left(\mathrm{CH}_{2}\right)_{2^{-}} ; 2.3-2.48,-\left(\mathrm{CH}_{2}\right)_{2^{-}}$.
$\mathrm{C}_{7} \mathrm{H}_{13} \mathrm{~S}^{+} \mathrm{SbF}_{6}^{-}\left(364.75 \mathrm{~g} \cdot \mathrm{mol}^{-1}\right)$
Calc.
C $25.09 \%$
H $3.88 \%$
Found
C $24.08 \%$
H $3.30 \%$

Synthesis of 2-methyl-2-propenyltetrahydrothiophenium hexafluoroantimonate (MAT) A mixture of $0.57 \mathrm{ml}(5.67 \mathrm{mmol})$ 3-bromo-2-methylpropene and $0.47 \mathrm{ml}(5.67 \mathrm{mmol})$ tetrahydrothiophene was reacted $1 \mathrm{~h}$ at room temperature. The whitish precipitate was dissolved in distilled water and washed with diethyl ether. Then an equimolar amount of $\mathrm{NaSbF}_{6}(1.46 \mathrm{~g})$ was added to the aqueous portion and a white precipitate of MAT was collected, washed with water and dried; m.p. $97-99^{\circ} \mathrm{C}$, yield $65 \%$.

${ }^{1} \mathrm{H}$ NMR $\left(\delta\right.$ in ppm): 5.2, $\mathrm{CH}_{2}=; 3.74,-\mathrm{CH}_{2}-\mathrm{S}^{+} ; 3.1-3.4,-\mathrm{S}^{+}-\left(\mathrm{CH}_{2}\right)_{2^{-}} ; 2$ - 2.3, - $\left(\mathrm{CH}_{2}\right)_{2}$; $1.95, \mathrm{CH}_{3}$.
$\mathrm{C}_{8} \mathrm{H}_{15} \mathrm{~S}^{+} \mathrm{SbF}_{6}^{-}\left(378.75 \mathrm{~g} \cdot \mathrm{mol}^{-1}\right)$
Calc.
C $25.34 \%$
H $3.96 \%$
Found
C $24.43 \%$
H $3.73 \%$ 


\section{Polymerization}

Appropriate solutions of monomer, sulfonium salt and radical initiator were mixed in pyrex tubes and degassed with nitrogen prior to irradiation by a merry-go-round type reactor equipped with 16 Philips $8 \mathrm{~W} / 06$ lamps emitting light at $\lambda>300 \mathrm{~nm}$. At the end of a given time, polymers were precipitated into methanol, filtered and dried.

\section{Characterization}

UV-Vis spectra were recorded on a Perkin-Elmer Lambda 2 spectrophotometer.

${ }^{1} \mathrm{H}$ NMR spectra were recorded on a Bruker $250 \mathrm{MHz}$ instrument. Elemental analyses were performed on a CHNS-932 LECO instrument.

\section{Results and discussion}

The allylic sulfonium salts were prepared by reacting the corresponding allylic bromide with tetrahydrothiophene followed by exchange reaction of $\mathrm{Br}^{-}$with $\mathrm{SbF}_{6}{ }^{-}$.

Scheme 1:

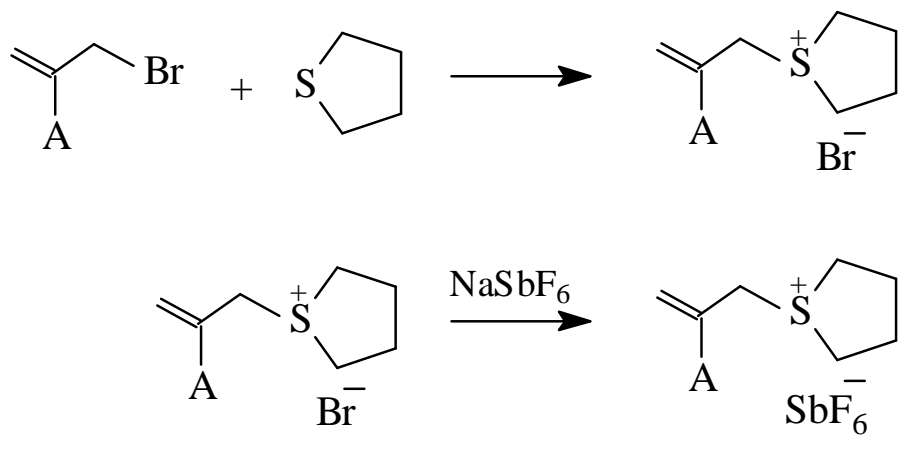

The structures of allylsulfonium salts were confirmed by means of spectral and elemental analysis. ${ }^{1} \mathrm{H}$ NMR spectra of the salts exhibit signals characteristic of allylic moiety in addition to the thiophene ring (see Exptl. part).

Allylsulfonium salts were used in the presence of photochemical free radical sources in order to give initial impact to activate the addition-fragmentation mechanism.

Benzoin and benzophenone were chosen as photochemical sources of free radicals. These compounds represent Type 1 and Type II photoinitiator families and upon irradiation undergo cleavage and $\mathrm{H}$-abstraction reactions, respectively, to generate free radicals [21].

As can be seen from Tab. 1, where the absorption characteristics of both free radical sources and allylic salts are collected, the allylic salts are transparent at the irradiation wavelength $(\lambda>300 \mathrm{~nm})$ and all the light emitted is absorbed by benzoin or benzophenone. 
Tab. 1. Absorption characteristics of allyl salts and radical photoinitiators

\begin{tabular}{|c|c|c|}
\hline Compound & $\lambda_{\max } / \mathrm{nm}$ & $\varepsilon /\left(\mid \cdot \mathrm{mol}^{-1} \cdot \mathrm{cm}^{-1}\right)$ \\
\hline benzoin & 250 & 13159 \\
& 280 & 1537 \\
& 350 & 81 \\
\hline benzophenone & 252 & 3156 \\
& 340 & 18 \\
\hline EAT & 228 & 125 \\
& 249 & 41 \\
\hline MAT & 262 & 405 \\
\hline AT & 262 & \\
\hline
\end{tabular}

Photopolymerization of $\mathrm{CHO}$ in the presence of allylsulfonium salts and benzoin

Benzoin and derivatives are frequently used as photoinitiators for radical vinyl polymerization due to their high quantum efficiencies of generating free radicals. In our combined system, both radicals formed from the photolysis of benzoin are expected to add to the double bond of the allylic salts. The subsequent fragmentation results in the formation of sulfonium radical cations which may directly initiate cationic polymerization. The high reactivity of sulfonium radical cations towards cyclohexene oxide monomer was investigated by Ledwith et al. [22] The analytical detection of the

Scheme 2:<smiles>O=C(c1ccccc1)[C@@H](O)[C@H](O)c1ccccc1</smiles>

R.

R. +

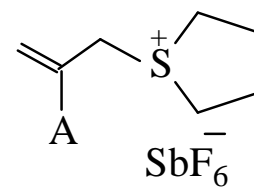<smiles>[R]CC([Y])C[S+]1CCCC1[SnH3]</smiles><smiles>[R][PH2]C=O</smiles><smiles>[R]CC(C)C[S+]1CCCC1[SnH3]</smiles> 
addition fragmentation products by GC-MS analysis of methanol soluble fractions after the polymerization is taken as an evidence for the initiation mechanism which involves addition-fragmentation.

Besides direct initiation, we also postulate that the initiation by sulfonium radical cations takes place by an indirect mechanism in which reactive Brønsted acids are formed by hydrogen atom abstraction from solvent or monomer and these species initiate the cationic polymerization of $\mathrm{CHO}$.

Scheme 3:

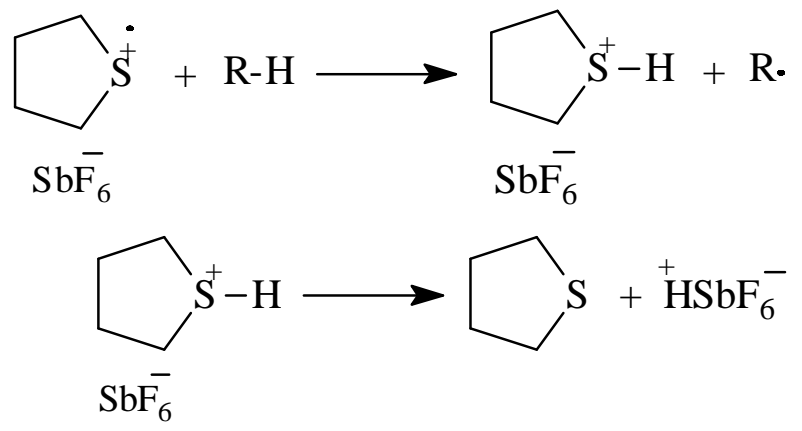

It should also be noted that there are also redox reactions accounting for the initiation. Nucleophilic hydroxybenzyl radicals can be oxidized to the corresponding carbocations by interaction with the ground state sulfonium ion as reduction potentials of allylsulfonium salts are suitable for electron transfer reactions [11].

Scheme 4:

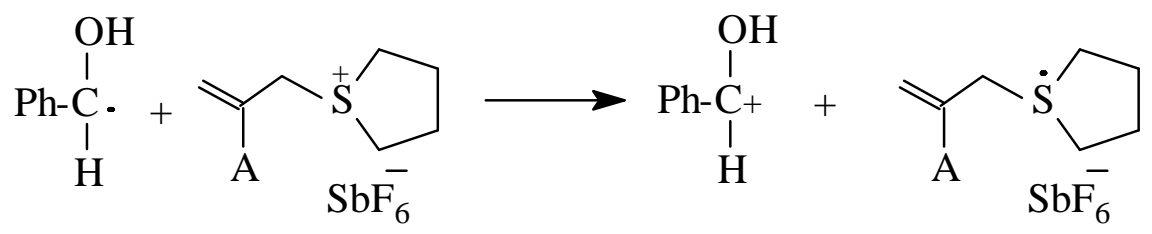

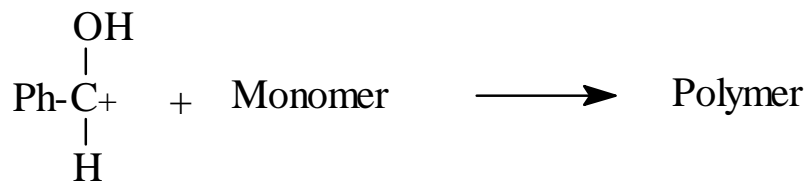

A comparison of the photoinitiated polymerization of $\mathrm{CHO}$ using three allylic salts with benzoin is shown in Fig. 1. The order of the increasing reactivity of the salts is as follows: AT, MAT and EAT. The observed order of activity can be ascribed to the contribution of the electron transfer mechanism. EAT and MAT are the two representatives with the highest susceptibility to oxidation reactions. In other words, the mechanism shown in Eqs. (8) and (9) involving the oxidation of hydroxybenzyl radicals stemming from benzoin by EAP or MAP probably accounts for the faster initiation. 


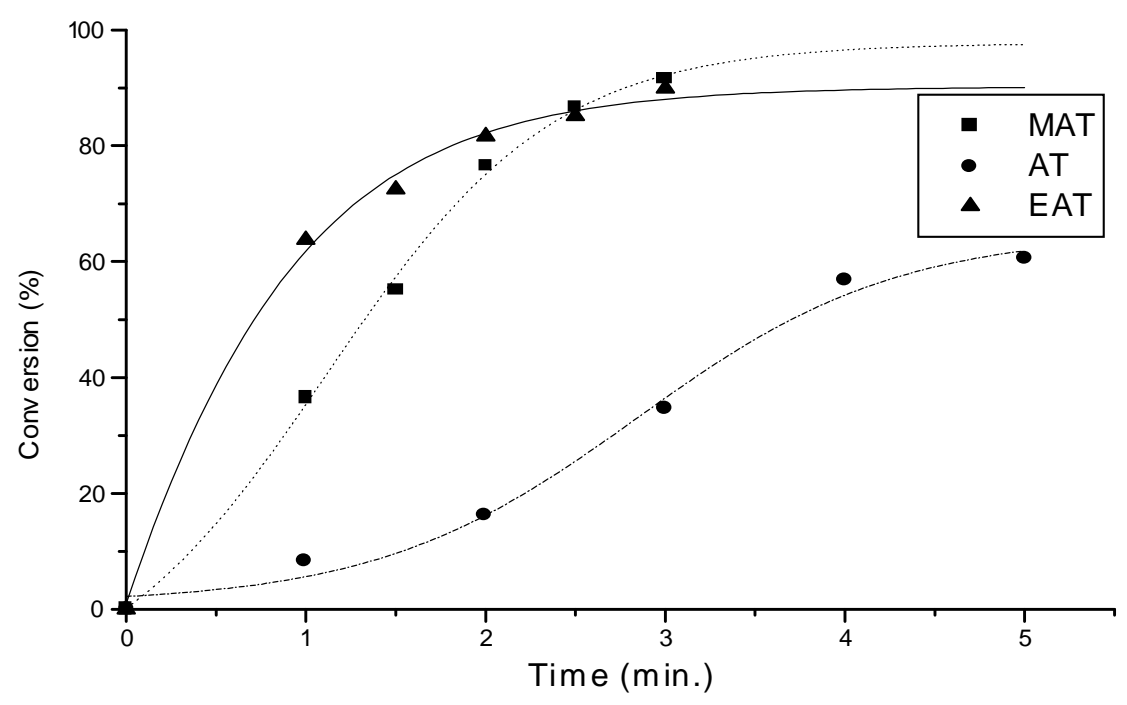

Fig. 1. Photoinitiated polymerization of $\mathrm{CHO}$ in the presence of allylsulfonium salts and benzoin. $\lambda>300 \mathrm{~nm}, \mathrm{OD}_{370 \mathrm{~nm}}$ (benzoin) $=0.1$, [benzoin $]=2.4 \times 10^{-2} \mathrm{~mol} \cdot \cdot^{-1}$, $[$ salt $]=5 \times 10^{-3} \mathrm{~mol} \cdot \mathrm{l}^{-1},[\mathrm{CHO}]=9.88 \mathrm{~mol} \cdot \mathrm{l}^{-1}$

Photopolymerization of $\mathrm{CHO}$ in the presence of allylsulfonium salts and benzophenone

Although benzophenone does not undergo photocleavage, it can still be regarded as a free radical photogenerator. Hydrogen abstraction by triplet benzophenone to give ketyl radicals is a well known process. Our earlier observation showed that the allylic salt itself is a good hydrogen donor [12] and photoexcited benzophenone abstracts hydrogen from allylsulfonium salt. Electron rich ketyl radicals thus formed are oxidized to give protonated ketones, which essentially yield protons to initiate cationic polymerization (Scheme 5).

Scheme 5:

$$
\mathrm{Ph}_{2} \mathrm{C}=\mathrm{O} \longrightarrow\left(\mathrm{Ph}_{2} \mathrm{C}=\mathrm{O}\right)^{*}
$$

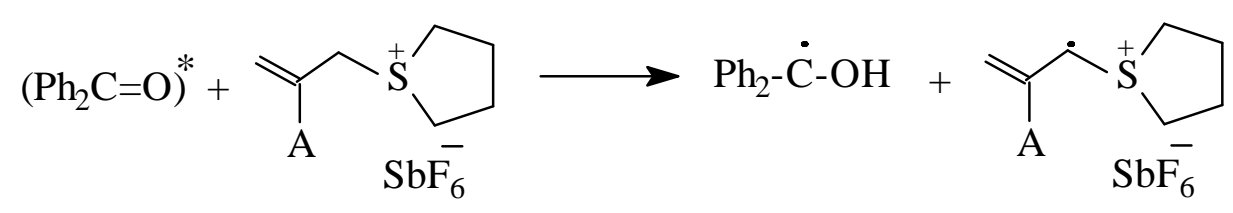

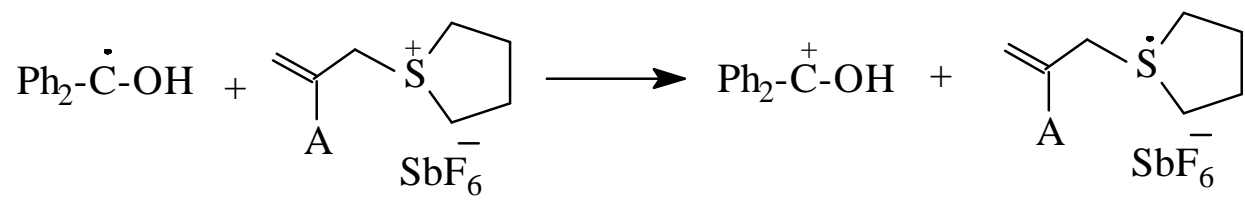

$$
\mathrm{Ph}_{2}-\stackrel{+}{\mathrm{C}}-\mathrm{OH} \longrightarrow\left(\mathrm{Ph}_{2} \mathrm{C}=\mathrm{O}\right)^{*}+\mathrm{H}^{+}
$$

$$
\mathrm{H}^{+}+\text {Monomer } \longrightarrow \text { Polymer }
$$




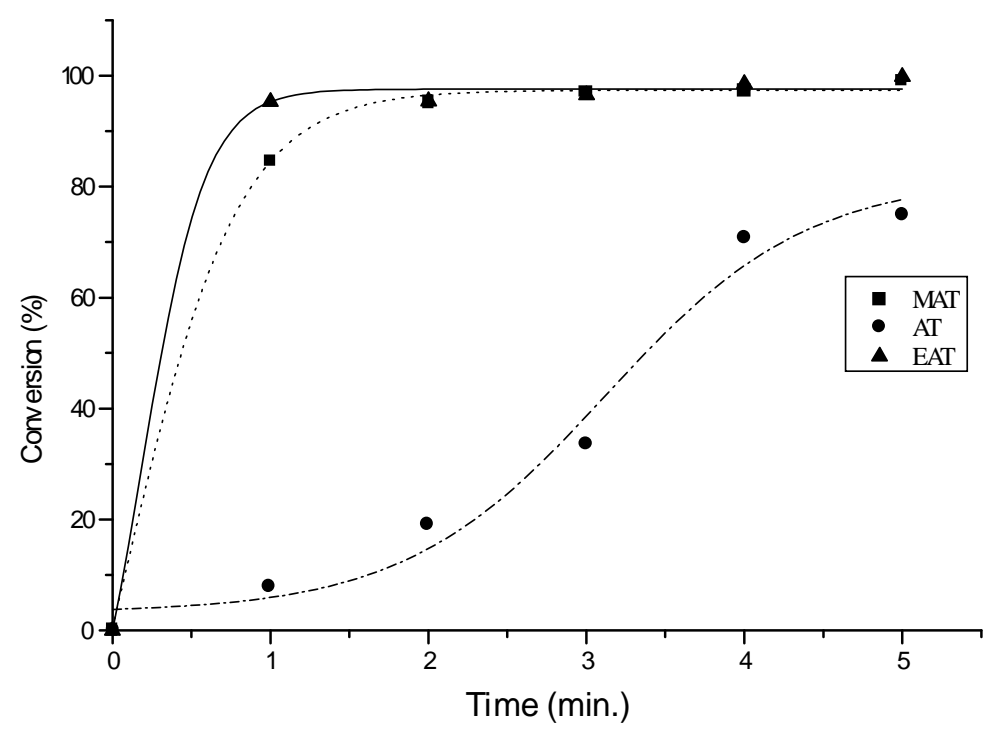

Fig. 2. Photoinitiated polymerization of $\mathrm{CHO}$ in the presence of allylsulfonium salts and benzophenone. [salt $]=[$ benzophenone $]=5 \times\left. 10^{-3} \mathrm{~mol} \cdot\right|^{-1},[\mathrm{CHO}]=\left.9.88 \mathrm{~mol} \cdot\right|^{-1}$

The direct electron transfer leading to the generation of photosensizer radical cation is disregarded due to the unfavourable thermodynamic conditions, i.e., $\Delta G=28.16$ $\mathrm{kJ} \cdot \mathrm{mol}^{-1}$. On the other hand, we cannot rule out an addition-fragmentation type initiation by radicals formed from the hydrogen donating components, i.e., allylic salt or solvent.

Fig. 2 shows the polymerization of $\mathrm{CHO}$ in the presence of allylsulfonium salts and benzophenone. Again, EAT and MAT initiated polymerizations are much faster compared to AT initiated polymerization of CHO. EAT and MAT initiated polymerizations reach limiting conversion values of $95 \%$ in 1 and 2 min, respectively, whereas limiting conversion of $75 \%$ is observed in $5 \mathrm{~min}$ for AT initiated polymerization. No polymer was obtained when bulk $\mathrm{CHO}$ and allyl sulfonium salts is irradiated at $\lambda_{\text {inc }}>300 \mathrm{~nm}$ in the absence of benzophenone.

In conclusion, allylsulfonium salts are efficient coinitiators for cationic polymerization when used in conjunction with free radical photoinitiators. Both cleavage and abstraction type photoinitiators can successfully be employed. The mechanism follows either the addition-fragmentation mechanism or involves the oxidation of free radicals depending on the coinitiator used. Differences in the initiation efficiency of allyl sulfonium salts are likely to be due to differences in the susceptibility to oxidation reactions.

Acknowledgement: The authors would like to thank Ciba, Specialty Chemicals (Switzerland) and Istanbul Technical University Research Fund for financial support. 
[1] Pappas, S.P.; "UV Curing Science and Technology", Norwalk, CT: Technology Marketing Corp., 1978.

[2] Dietliker, K.; "Chemistry \& Technology of UV \& EB Formulation for Coatings, Inks \& Paints", London: SITA Technology Ltd., 1991, Vol.III.

[3] Crivello, J.V.; J. Polym. Sci., Polym. Chem. Ed. 1999, 37, 4241.

[4] Crivello, J.V.; Lam, J.H.W.; J. Polym. Sci., Polym. Chem. Ed. 1980, 18, 2677.

[5] Crivello, J.V.; Lam, J.H.W.; Macromolecules 1977, 10, 1307.

[6] Yagcl, Y.; Schnabel, W.; Macromol. Chem., Macromol. Symp. 1992, 60, 133.

[7] Bottcher, A.; Hasebe, K.; Hızal, G.; Stelberg, P.; Yagci, Y.; Polymer 1991, 32, 2289.

[8] Yagci, Y.; Lukac, I.; Schnabel, W.; Polymer 1993, 34, 1130.

[9] Hizal, G.; Yagci, Y.; Schnabel, W.; Polymer 1994, 35,2428.

[10] Yagci, Y.; Reetz, I.; Prog. Polym. Sci. 1998, 23, 1485.

[11] Denizligil, S.; Yagci, Y.; McArdle, C.; Polymer 1995, 36, 3093.

[12] Denizligil, S.; Resul, R.; Yagci, Y.; McArdle, C.; Fouassier, J.P.; Macromol. Chem. Phys. 1996, 197, 1233.

[13] Yagci, Y.; Onen, A.; J. Polym. Sci., Polym. Chem. 1996, 34, 3621.

[14] Reetz, I.; Bacak, V.; Yagci, Y.; Macromol. Chem. Phys. 1997, 198, 19.

[15] Reetz, I.; Bacak, V.; Yagci, Y.; Polym. Int. 1997, 43, 27.

[16] Atmaca, L.; Onen, A.; Yagci, Y.; Eur.Polym.J. 2001, 37, 677.

[17] Onciu, M.; Onen, A.; Yagci, Y.; Polym. Int. 2001, 50, 144.

[18] Yagci, Y.; Yıldırım, S.; Onen, A.; Macromol. Chem. Phys. 2001, 202, 527.

[19] Onen, A.; Yagci, Y.; Polymer 2001, 42, 6681.

[20] Onen, A.; Yagci, Y.; Macromol. Chem., in press.

[21] Davidson, S.; "Exploring the Science, Technology and Applications of U.V. and E.B. Curing", SITA Technology Ltd., London 1999, p.70.

[22] Ledwith, A.; Al-Kass, S.; Hulme-Lowe, A.; "Cationic Polymerization and Related Processes", editor E. J. Goethals, Academic, London 1984, p.275. 